\title{
About the Bi-Mobile Planar Mechanisms STRUCTURAL DESIGN
}

\section{Comanescu, A.; Comanescu, D. \& Dugaesescu, I.}

Abstract: The bi-mobile planar mechanisms may be found in various technique applications. The effectors extremity of such mechanism describes any curve in an adequate domain. Having in view the kinematic chains with five degree of freedom (Crossley, 1968; Manolescu et all., 1972, Pelecudi 1967) the mechanisms solutions are deduced. The paper deals with a general method for the bi-mobile planar mechanisms design. By using a kinematic chain it is necessary to nominate the basis, the effector and to select the active pairs (actuators) of the system. Such mechanisms are generally used for robot arms or legs for mobile platforms.

Key words: bi-mobile planar mechanism, structure, design, robot arm, pedipulator
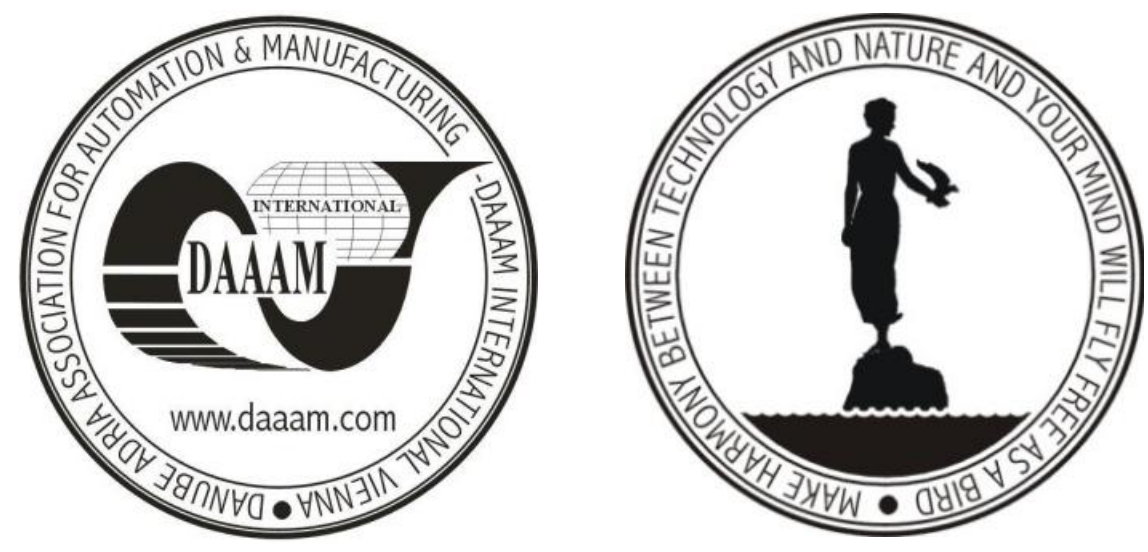

Authors' data: Univ.Prof.Ing. Comanescu, A[driana]; Univ.Prof.Ing. Comanescu, $\mathrm{D}$ [inu]; Univ.Lect.Ing. Dugaesescu, I[leana], University POLITEHNICA of Bucharest, Splaiul Independentei 313, 060042, Bucharest, Romania, adrianacomanescu@yahoo.com, dinucomanescu@yahoo.com, ileana_d1 yahoo.com

This Publication has to be referred as: Comanescu, A[driana]; Comanescu, D[inu] \& Dugaesescu, I[leana] (2012). About the Bi-Mobile Planar Mechanisms Structural Design, Chapter 28 in DAAAM International Scientific Book 2012, pp. 327-338, B. Katalinic (Ed.), Published by DAAAM International, ISBN 978-3-901509-86-5, ISSN 1726-9687, Vienna, Austria

DOI: $10.2507 /$ daaam.scibook.2012.28 
Comanescu, A.; Comanescu, D. \& Dugaesescu, I.: About the Bi-Mobile Planar Me...

\section{Introduction}

Having in view the structural solutions found in the literature (Crossley, 1968; Manolescu et all., 1972, Pelecudi 1967) the paper deals with the problem of the bimobile planar mechanisms structural design. The bi- mobile planar mechanisms are currently used for the construction of robot arms and legs - pedipulators for the mobile robots. The extremity of the mechanism effectors may describe any curve in a suitable domain of the mechanisms. Due to his fact such mechanisms are also used for mechanisms of adjustment and positioning.

\section{Structural solutions of bi-mobile planar mechanisms}

The structural solutions of bi-mobile mechanisms in function of the contour number may be obtained from the linkages solutions found in the literature (Fig.1). These solutions are characterized by their 5 degrees of freedom and the contours number (Crossley, 1968; Manolescu et all., 1972, Pelecudi 1967).

\begin{tabular}{|l|l|}
\hline & \\
\hline
\end{tabular}




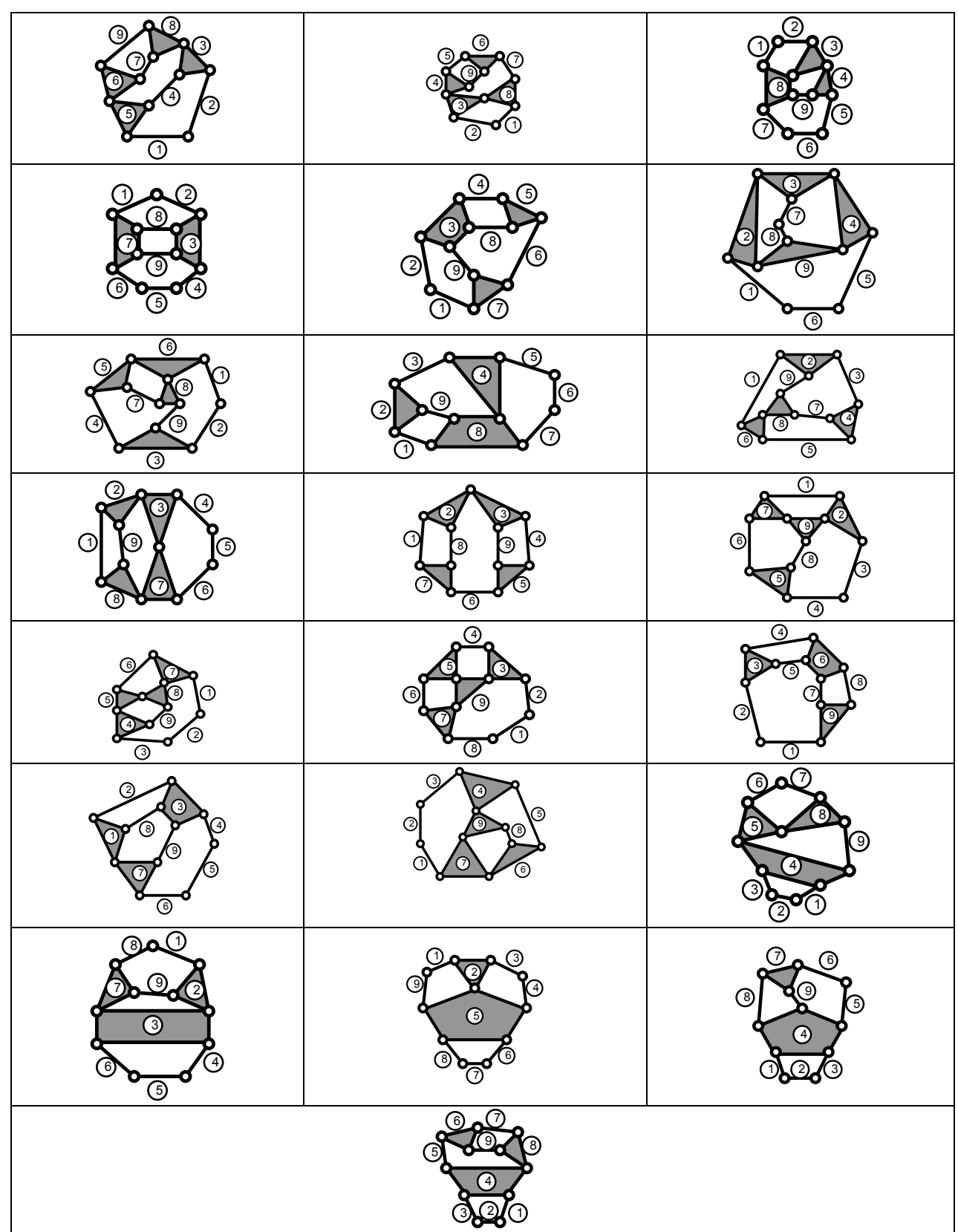

Fig. 1. Planar linkages with five degrees of freedom

In order to obtain solutions for bi-mobile mechanisms it is necessary to adopt a linkage from Fig. 1 and to make the following steps:

- to mention the possible bases and effectors;

- to verify the solutions for bases and effectors through the inverse structural model characterized by a zero instantaneous degree of mobility;

- the selection of the optimum structural-constructive solutions including a minimum number of passive modular groups;

- to place in the mechanism structure the active kinematic pairs (actuators);

- by means of the direct structural models to select the optimum structuralconstructive including a minimum number of active and passive modular groups.

In the structure of planar mechanisms there are included passive and active groups. These are open and un-decomposable linkages either zero degree of mobility 
Comanescu, A.; Comanescu, D. \& Dugaesescu, I.: About the Bi-Mobile Planar Me...

in the case of passive groups or positive degree of mobility in the case of active modular groups.

Such passive modular groups are shown in Fig.2. Some active mono-mobile modular groups are given in Fig.3 and the bi-mobile ones in Fig.4.

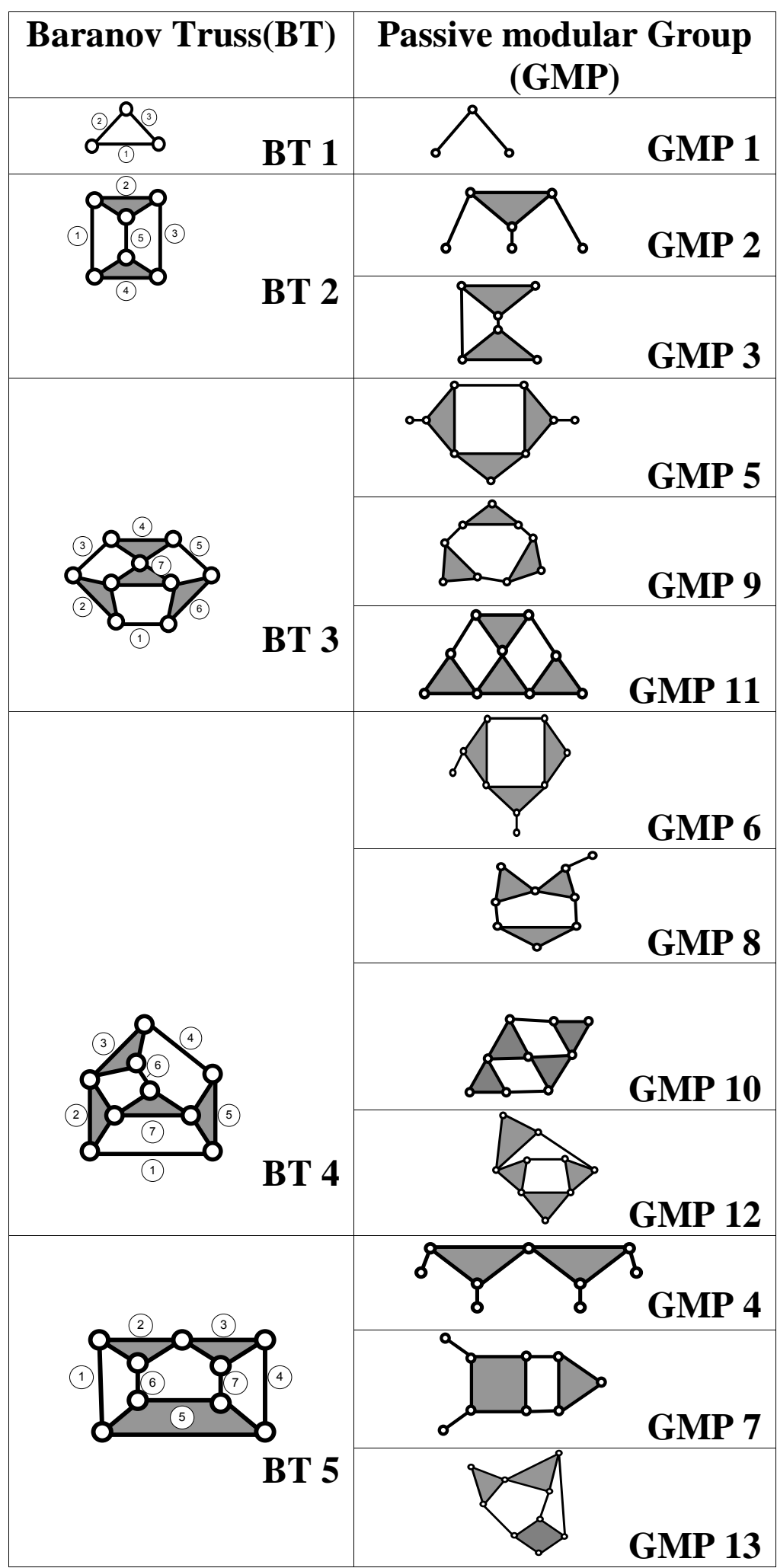

Fig. 2. The passive modular groups 


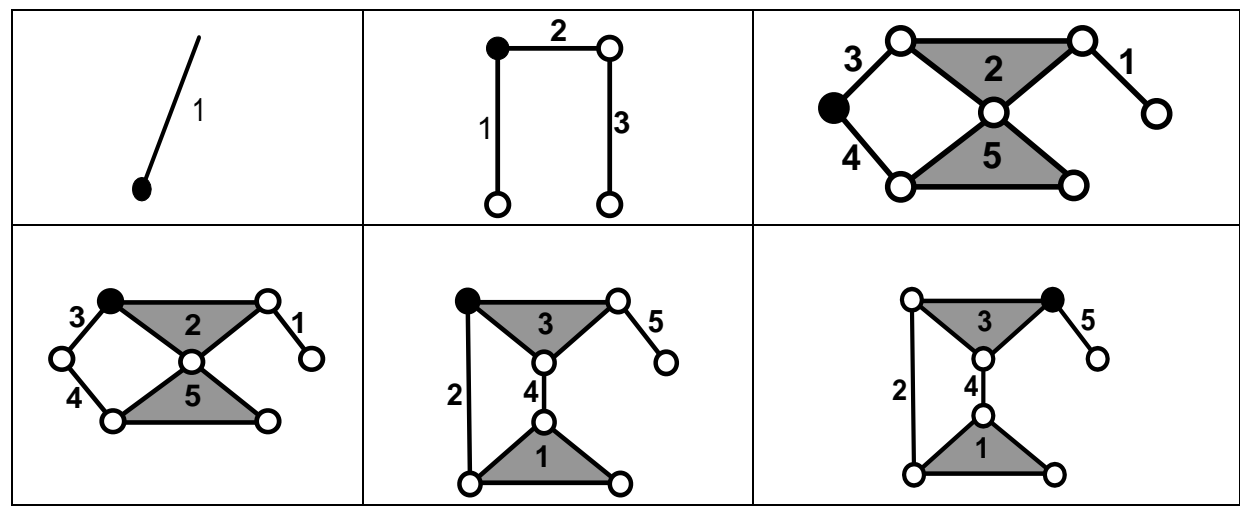

Fig. 3. The mono-mobile active modular groups

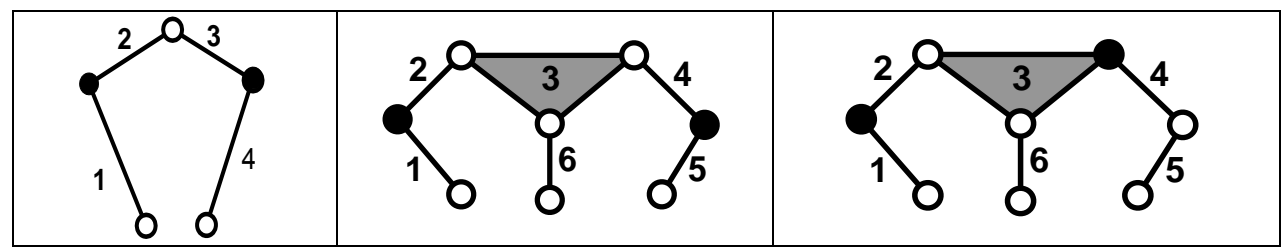

Fig. 4. The bi-mobile active modular groups

One may note that the active pair is drawn in black (Fig.3, 4).

The construction of the Stewart platform bi-mobile leg (pedipulator) given in Fig.5 is based on the linkage (Fig.6) with five degrees of freedom, that is two degree of mobility.

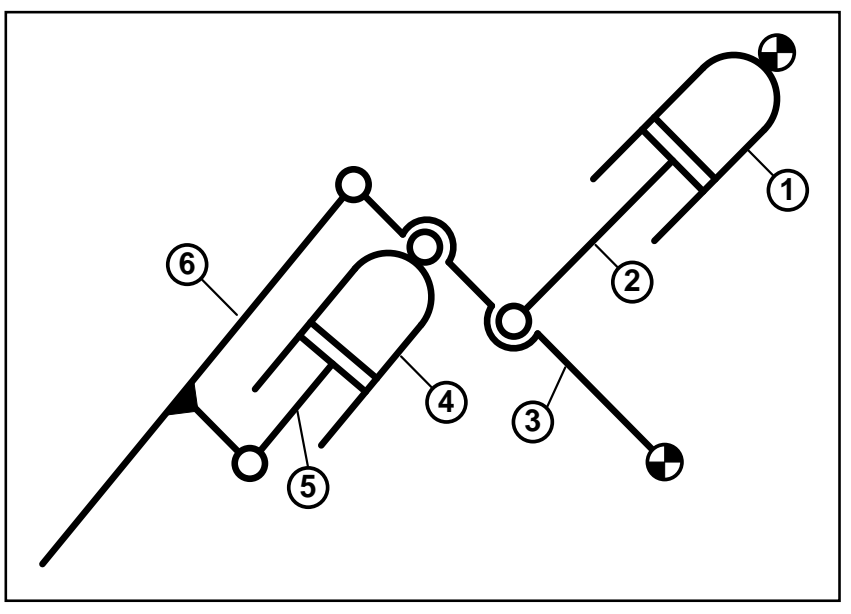

Fig. 5. The Stewart platform bi-mobile leg

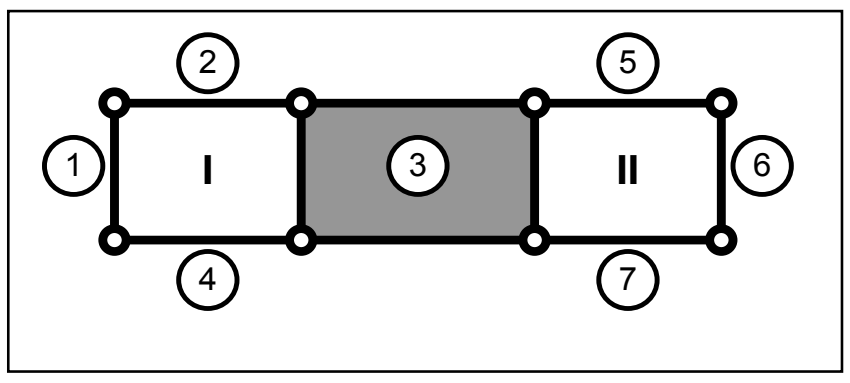

Fig. 6. The structural model of the Stewart platform bi-mobile leg 
The inverse structural model given in Fig.7 has three passive modular groups of dyad type (Fig.2).

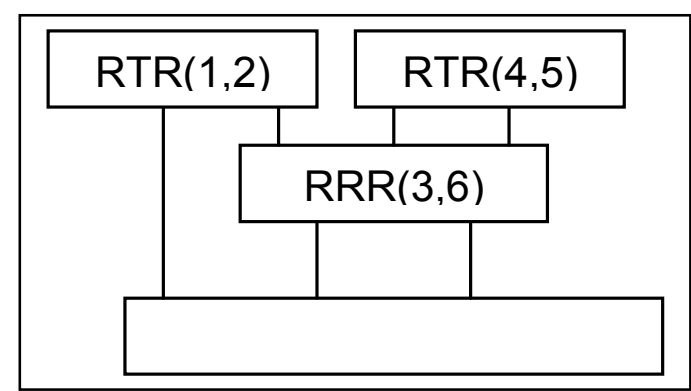

Fig. 7. The inverse structural model

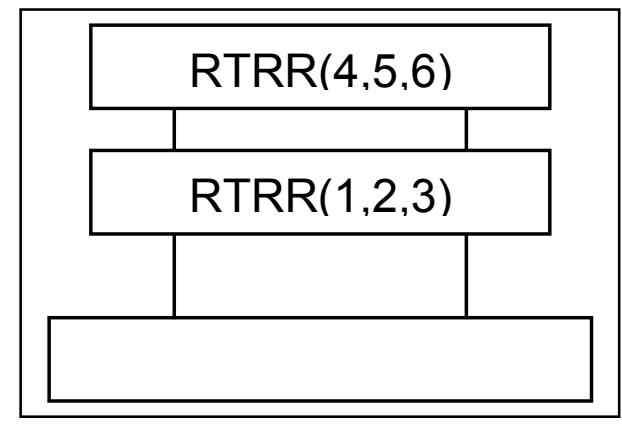

Fig. 8. The direct structural model

The direct structural model presented in Fig.8 is composed by two active modular groups of the RTRR type (Fig.3).

For the following constant parameters of the Stewart pedipulator (Fig.9) expressed in $[\mathrm{m}]$ :

$$
\begin{array}{cccc}
\mathrm{XA}=0 & \mathrm{YA}=0 \quad \mathrm{XD}=0 & \mathrm{YD}=-0.03 \\
\mathrm{DE}=0.06 & \mathrm{DC}=0.03 \quad & \mathrm{TE}=0.07 \\
\mathrm{GK}=0.025 \quad \mathrm{DF}=0.045 \quad \mathrm{BC}=0.15 \quad \mathrm{TK}=0.03
\end{array}
$$

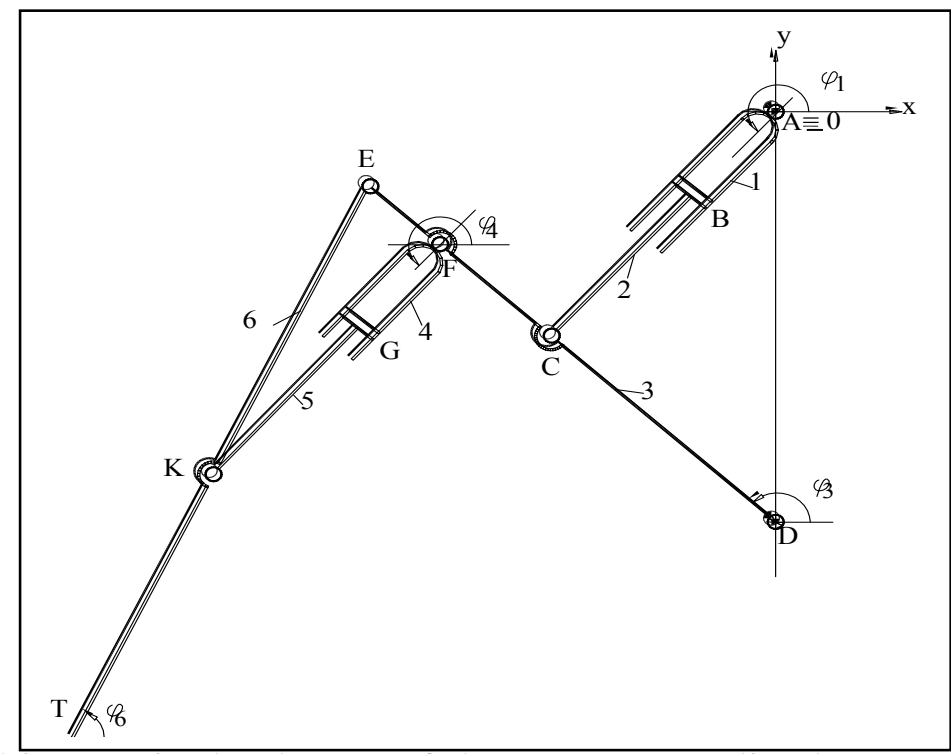

Fig. 9. The kinematical scheme of the Stewart pedipulator

and a linear trajectory with a constant velocity for the T point given in Fig.10 


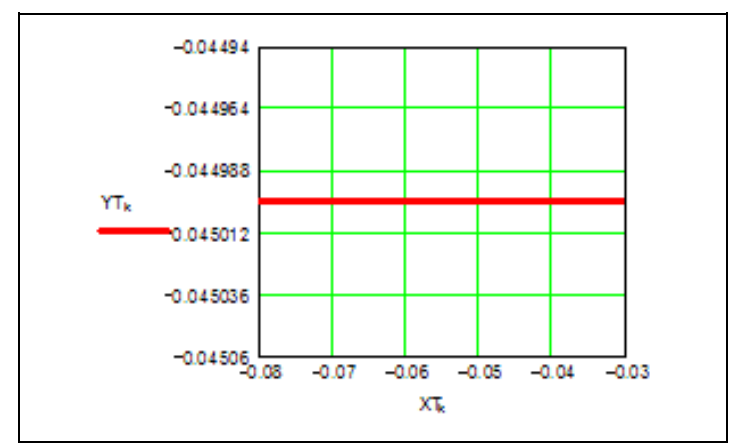

Fig. 10. The $\mathrm{T}$ point linear trajectory

It is possible to determine the characteristic parameters of the $B$ and $G$ active prismatic pairs (Fig.11) by using the inverse structural model (Fig.7) and the variation of $\mathrm{FK}$ and $\mathrm{AC}$.

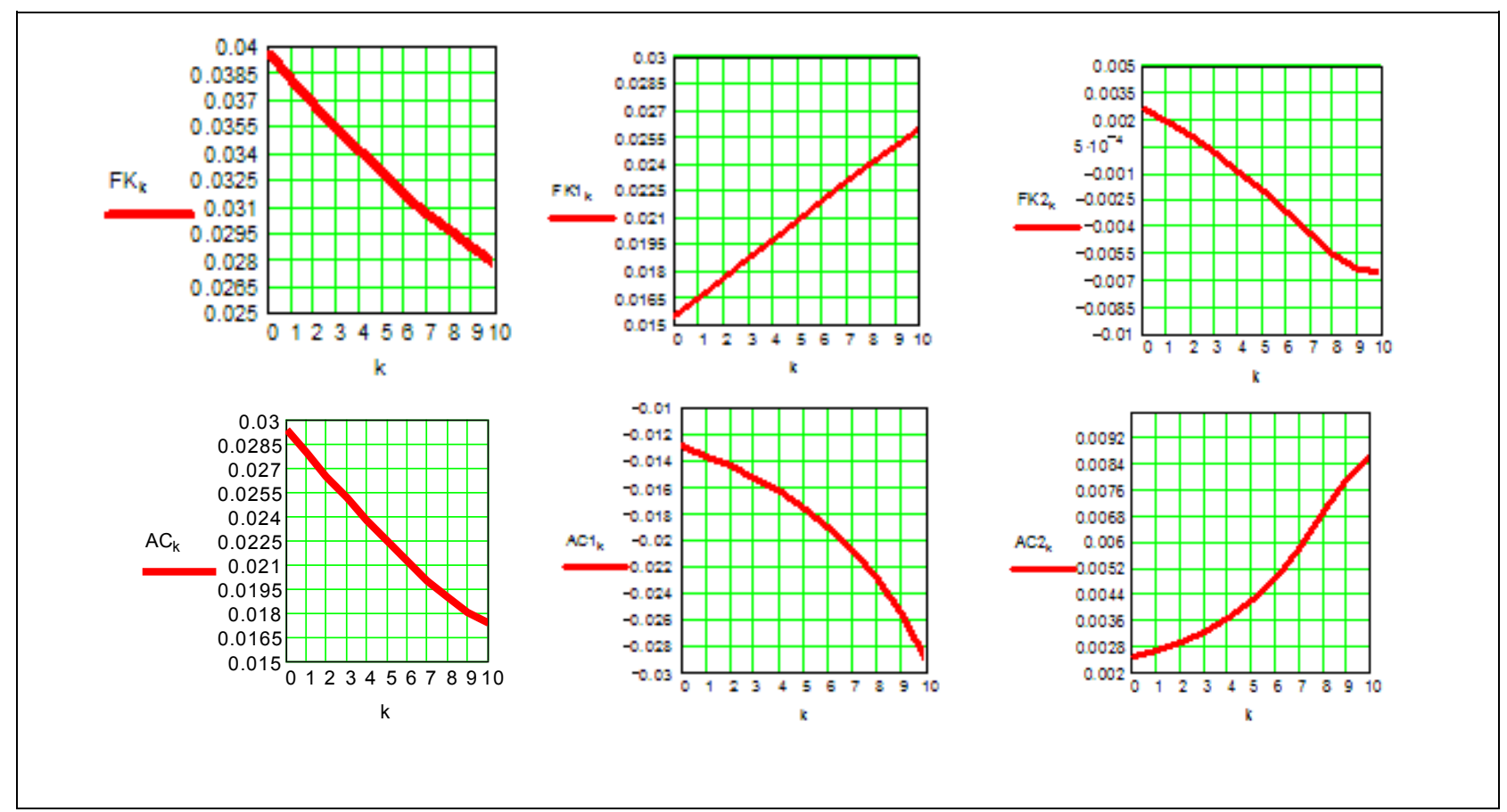

Fig. 11. The characteristic parameters of the $\mathrm{B}$ and $\mathrm{G}$ active prismatic pairs

By means of the direct structural model there are determined the inner forces between the 1 and 2 links denoted by T12 and respectively T54 the force between the 4 and 5 links (Crossley, 1968). Their variations for the T point trajectory (Fig.10) are given in Fig.12.

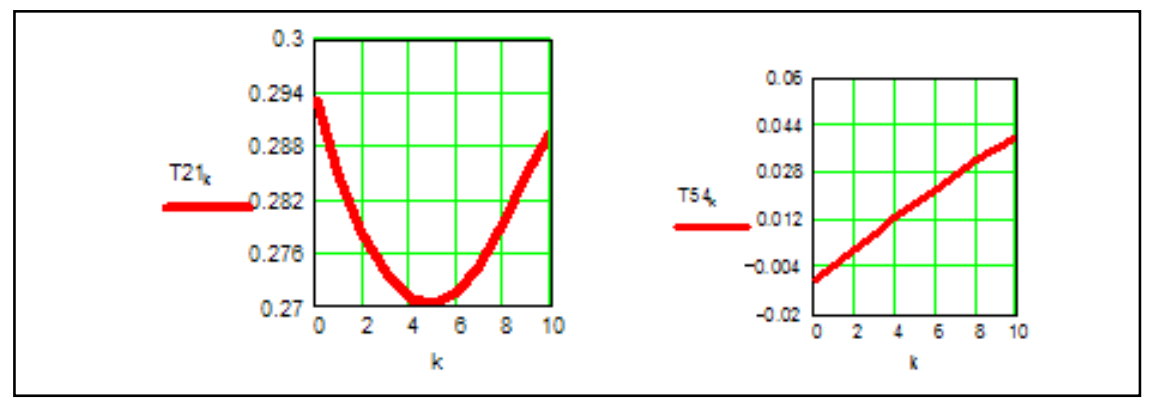

Fig. 12. The variations of the active pair inner forces 
Comanescu, A.; Comanescu, D. \& Dugaesescu, I.: About the Bi-Mobile Planar Me...

The mass characteristics of the mechanism links are the following:

$\mathrm{G} 1=\mathrm{G} 2=\mathrm{G} 4=\mathrm{G} 5=0.049 \mathrm{~kg} ; \mathrm{G} 3=\mathrm{G} 6=0.098 \mathrm{~kg}$.

\section{The structural and constructive design of a bi-mobile planar mechanism for a pedipulator}

For the structural design of a bi-mobile planar mechanism it is possible to select a linkage characterized by 5 degrees of freedom and respectively by 2 degrees of mobility from Fig.1.

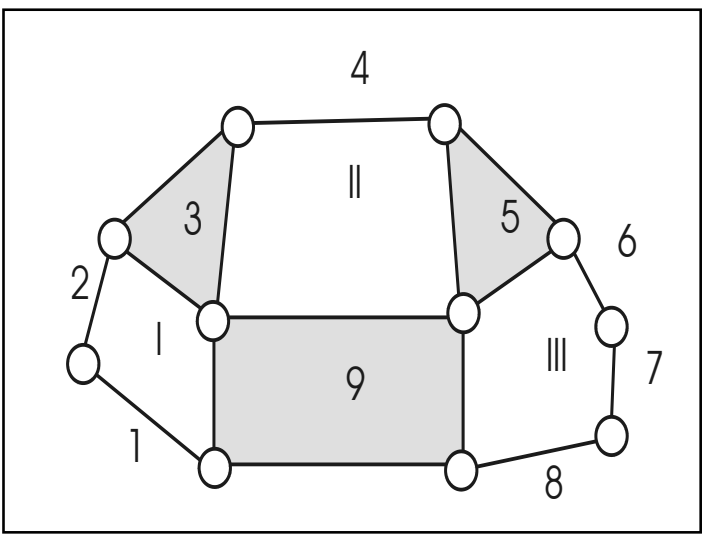

Fig. 13. The selected bi-mobile linkage

The linkage has 9 links, 11 lower kinematic pairs and 3 independent contours.

For the selection of the basis and the effector it is necessary to have in view the following theorems:

- the effector must have a planar motion depending to two independent parameters;

- the effector can not be adjacent to the basis;

- the basis and the effector can not belong to the same four bars linkage (Fig.14 a), Watt linkage (Fig.14 b) or Stephenson linkage (Fig.14 c).

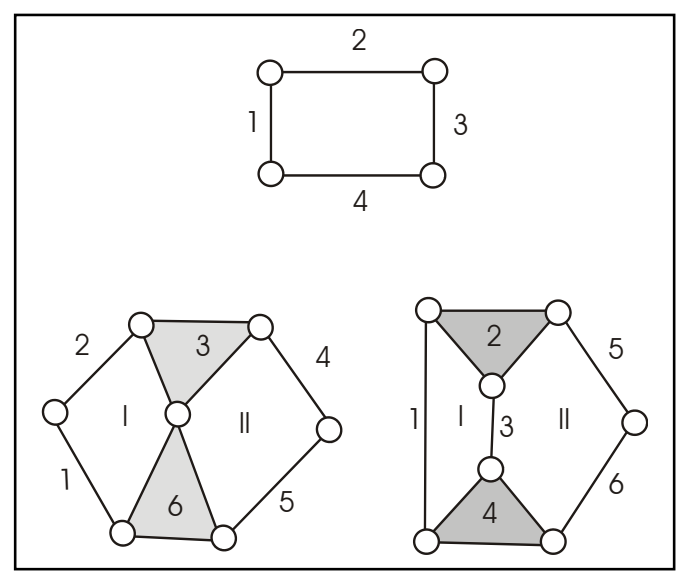

Fig. 14. a) Four bars linkage, b) Watt linkage, c) Stephenson linkage

Having in view the previous theorems it is possible to determine the basiseffector matrix 


\begin{tabular}{|c|c|c|c|c|c|c|c|c|c|}
\hline link & 1 & 2 & 3 & 4 & 5 & 6 & 7 & 8 & 9 \\
\hline 1 & 0 & 0 & 0 & 0 & 0 & 1 & 1 & 1 & 0 \\
\hline 2 & 0 & 0 & 0 & 0 & 0 & 1 & 1 & 1 & 0 \\
\hline 3 & 0 & 0 & 0 & 0 & 0 & 1 & 1 & 1 & 0 \\
\hline 4 & 0 & 0 & 0 & 0 & 0 & 1 & 1 & 1 & 0 \\
\hline 5 & 0 & 0 & 0 & 0 & 0 & 0 & 1 & 1 & 0 \\
\hline 6 & 1 & 1 & 1 & 1 & 0 & 0 & 0 & 1 & 1 \\
\hline 7 & 1 & 1 & 1 & 1 & 1 & 0 & 0 & 0 & 1 \\
\hline 8 & 1 & 1 & 1 & 1 & 1 & 1 & 1 & 0 & 1 \\
\hline 9 & 0 & 0 & 0 & 0 & 0 & 1 & 1 & 0 & 0 \\
\hline
\end{tabular}

The matrix is square, symmetric and the null elements of the principal diagonal, because the basis can not be in the same time effector.

From this matrix one may select the 1 link as a basis and the 6 link as an effector.

The inverse structural model is characterized by a null instantaneous degree of mobility which corresponds to impose two parameters for the effector. This fact may be possible when a higher pair connects the basis with the effector. In the mentioned case the inverse structural model is given in Fig.15.

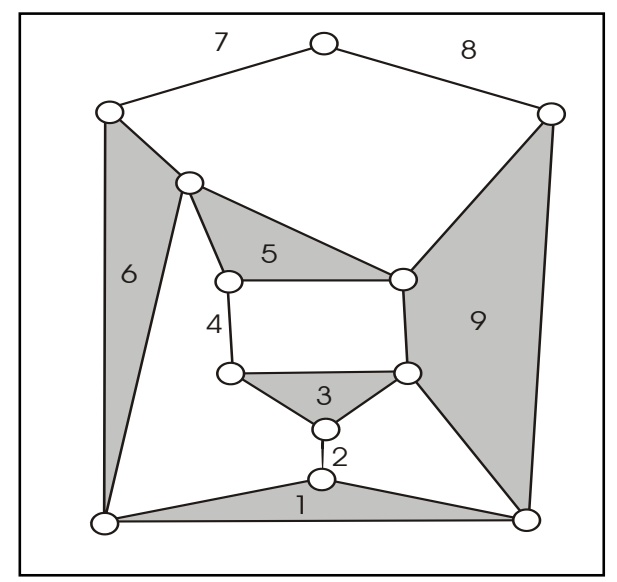

Fig. 15. The inverse structural model

The inverse structural model exclusively contains passive modular groups, which are open and indecomposable linkages with zero degree of mobility.

In the literature there are only mentioned 13 passive modular groups (Fig.2), others may be deduced by means of the 33 Baranov trusses. 
The effector must belong to the first passive modular group connected to the basis. A mechanical system is more performing if it contains a minimum number of passive groups.

In Fig.16 there are put into evidence the passive modular groups, which belongs to the inverse modular model.

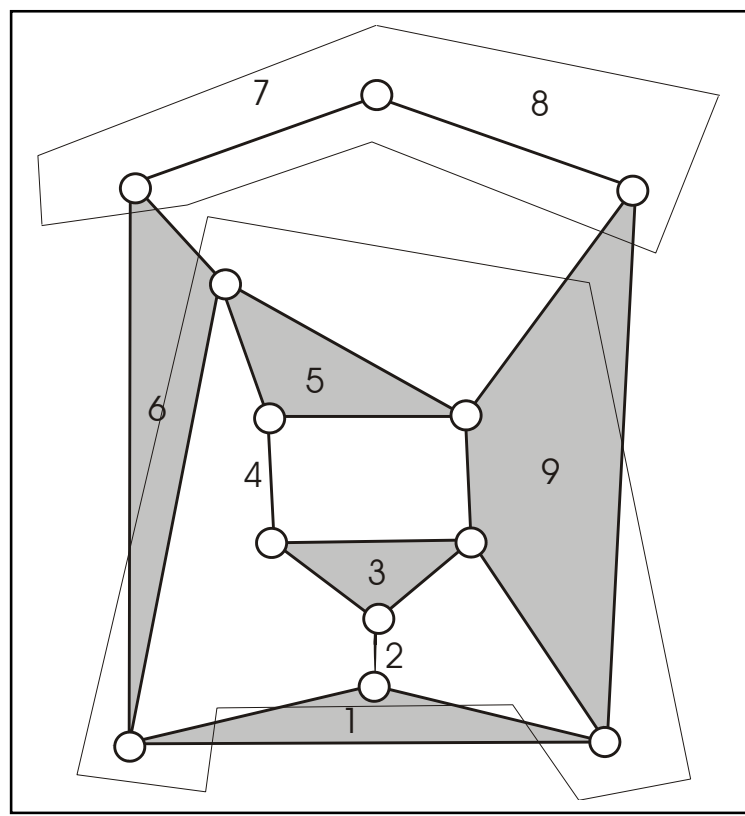

Fig. 16. The inverse modular model with the passive modular groups

In the inverse model there are the $\operatorname{GMP}(2,3,4,5,6,9)$ passive modular group (Fig.17) identified in Fig.2 as GMP5 and the $\operatorname{GMP}(7,8)$ passive group of dyad type (Fig.18).

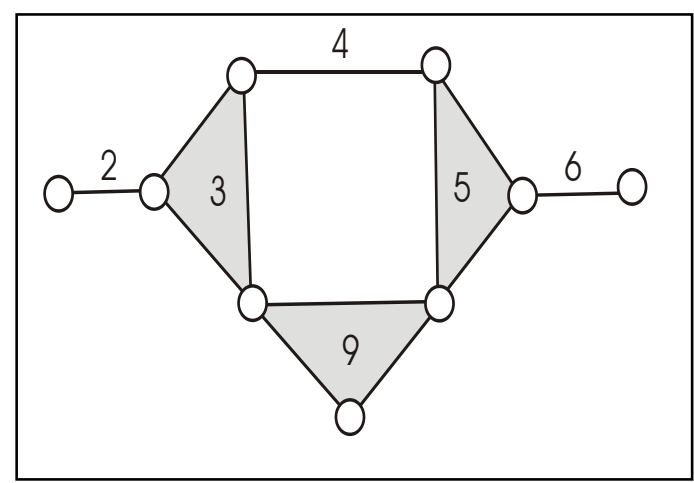

Fig. 17. The $\operatorname{GMP}(2,3,4,5,6,9)$ passive modular group

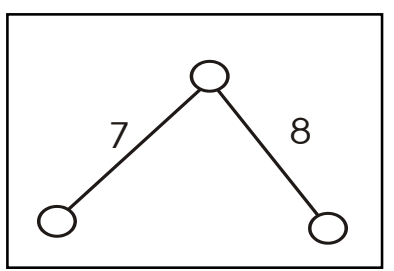

Fig. 18. The $\operatorname{GMP}(7,8)$ passive group

The modular groups connection is presented in Fig. 19. 


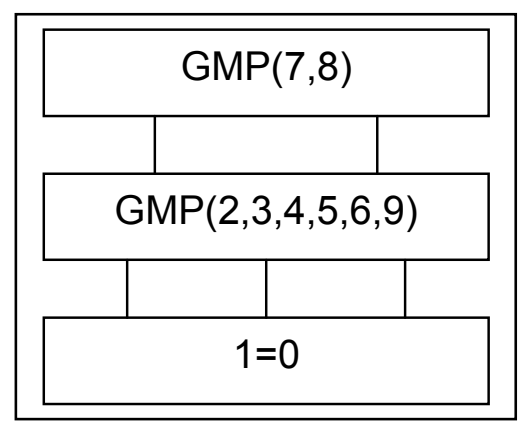

Fig. 19. The modular groups connection

The placement of the active pairs in the system must satisfy the following theorem:

- in a four class contour a single active pair may be placed;

- in the Watt or Stephenson linkage a single active pair may be placed.

The direct model is optimally built with a minimum number of modular groups. For the linkage given in the Fig. 13 one may note that in the contour I may be placed an active pair, in the contours I and II may have only one active pair and in the contour III two active pairs may be placed. In the contour III an active modular group with two degrees of mobility with two active pairs may be obtained. The active pairs may be placed between the $(5,6),(6,7),(7,8),(8,9)$ links existing $\mathrm{C}_{4}{ }^{2}=6$ solutions , that is the active pairs between $(5,6)+(6,7) ;(5,6)+(7,8) ;(5,6)+(8,9) ;(6,7)+(7,8)$; $(6,7)+(8,9)$ or $(7,8)+(8,9)$.

In the case in which there are used the active pairs $(7,8)$ and $(8,9)$ the structural model (Fig.20) contains a single active modular group with two degrees of mobility (Fig.21).

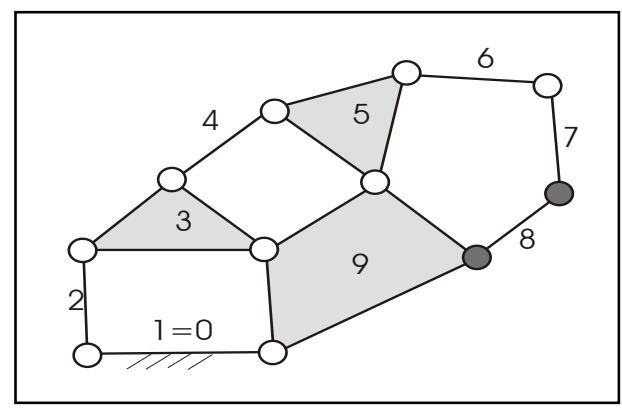

Fig. 20. The bi-mobile mechanism

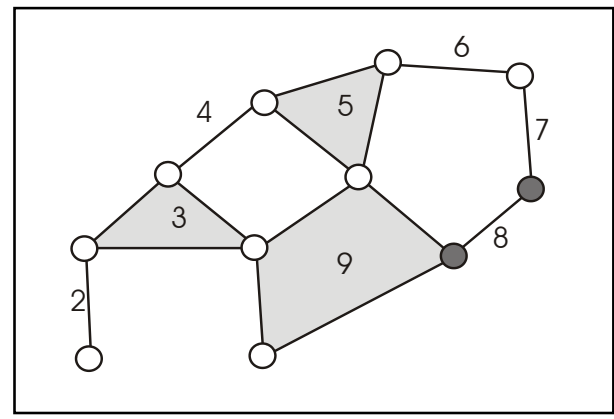

Fig. 21. The structural model of the bi-mobile mechanism 
For the structural model (Fig.20) one may achieve the constructive model given in Fig.22.

Fig. 22. The designed bi-movire mecnanism

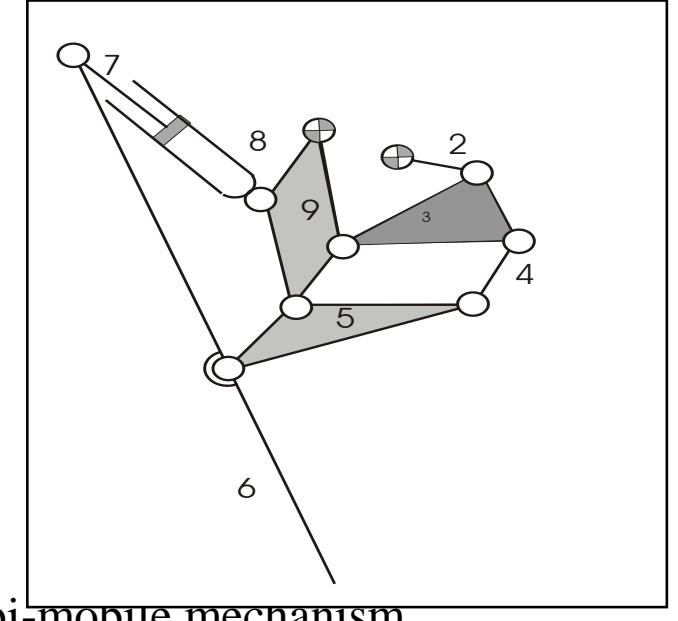

The bi-mobile pedipulator mechanism has the capacity to attain with the extremity of its effector 6 any point in a determined planar domain.

\section{Conclusions}

The paper deals with a general method to design bi-mobile planar mechanisms for various purposes. There are used structural solutions for linkages with various degrees of freedom mentioned in the literature (Crossley, 1968; Manolescu et all., 1972, Pelecudi 1967). By applying the method new configurations for robot arms or for pedipulators - systems for sustaining and displacement of mobile platforms may be found.

\section{Acknowledgements}

The paper was achieved for the project entitled "Exploitation of Cultural Identities in global processes" co financed by the European Union and the Government of Romania from European Social Fund through the Operational Sectorial Program for the Human Resources Development", POSDRU/89/1.5/S/59758 financial contract.

\section{References}

Crossley, F.R.E. (1968). Structural Synthesis of a Four Bit Binary Adding Mechanisms, 10-th ASME Mechanisms Conference, Paper no.68 MECH 25 Atlanta 6-9 Oct.1968

Manolescu, N., Kovacs, Fr., Orănescu, A. (1972). Teoria mecanismelor şi a maşinilor, Editura Didactică şi Pedagogică, Bucureşti

Pelecudi, Chr. (1967) Bazele analizei mecanismelor, Editura Acadmiei Române, București

Voinea, R., Stroe, I. (2000). Mechanical Structures Dynamics, Editura Academiei Române, București 